\title{
O FUNCIONAMENTO DE TIPOLOGIAS DISCURSIVAS EM LIVROS DIDÁTICOS DE HISTÓRIA
}

Raquel Alvarenga Sena Venera*

RESUMO: Este artigo é parte dos resultados da pesquisa de doutorado intitulada Discursos educacionais na construção das subjetividades cidadãs e implicações no ensino de História: um jazz possível, cujo objetivo específico era analisar a operacionalização dos discursos educacionais pós-abertura política nos livros didáticos de História indicados para os anos finais do ensino fundamental, pelo Guia do Livro Didático 2005. A pesquisa privilegiou metodologicamente a análise do discurso, $\mathrm{AD}$, da corrente francesa, e, dessa forma, possibilitou perceber o funcionamento discursivo de duas coleções de livros didáticos mais escolhidas pelos professores do município de Itajaí, SC - as coleções Nova História Crítica, de autoria de Mario Furley Schimidt, publicada pela editora Nova Geração, e História \& Vida Integrada, de autoria de Nelson Piletti e Claudino Piletti, da editora Ática. Por caminhos diferentes, os livros didáticos fazem funcionar sentidos de democracia, de cidadania e de regulação dos sentidos das subjetividades em processo.

Palavras-chave: Educação; Políticas Educativas; Livro Didático.

\section{THE OPERATION OF DISCURSIVE TYPOLOGIES IN HISTORY TEXTBOOKS}

ABSTRACT: This article is part of the results of a doctoral research entitled "Education Discourses in the construction of subjectivities of citizenship and implications in the Teaching of History: a possible jazz", whose specific aim was to examine the operation of educational discourses, after the political liberalization policy, in the History textbooks indicated for the final years of fundamental education by the Textbook Guide-2005. The research methodology focused on the Discourse Analysis, AD, the French line, and this way enabled the understanding of the discursive operation of the two textbook collections most chosen by teachers in the municipality of Itajaí, state of Santa Catarina: "Nova História Crítical”, by Mário Furley Schimidt, published by Editora Nova Geração; and "História \& Vida Integrada", authored by Nelson Piletti and Claudino Piletti, Attica publishers. Through different ways, the textbooks operate the meanings of democracy, citizenship and regulation of senses of the subjectivities in process.

Keywords: Education; Educational Policies; Textbook.

\footnotetext{
*Doutora em Educação pela Universidade Estaudal de Campinas (UNICAMP); professora dos Cursos de Mestrado em Educação e Mestrado em Patrimônio Cultural e Sociedade, ambos da Universidade da Região de Joinville (UNIVILLE). E-mail: raquelsenavenera@hotmail.com; raquel.venera@univille.br
} 


\section{INTRODUCุÃO}

Este artigo investe na possibilidade de análises de livros didáticos de História que se deslocam dos resultados bastante consolidados nas pesquisas no ensino de História - as análises de conteúdos dos livros e as apropriações de estudantes e professores - para um local que evidencia o funcionamento dos discursos dos livros. Circe Bittencourt (2008) faz um breve mapa de como têm se construído as pesquisas no ensino de História sobre os livros lidáticos. A autora afirma que, no Brasil, as pesquisas sobre livros didáticos que enfocam uma perspectiva ideológica são comuns. São aquelas que analisam os conteúdos escolares. E, entre as análises de conteúdo também se encontram aquelas pesquisas que verificam a defasagem entre a produção acadêmica e a escolar, ou estereótipos, ou ausência das histórias de grupos étnicos ou minoritários na sociedade brasileira. Todavia, desde o VII Encontro Nacional dos Pesquisadores do Ensino de História, ENPEH, o coordenador do GT sobre livro didático, Kazumi Munakata, anunciou em seu relatório que mais de $40 \%$ dos trabalhos apresentados no GT partiram do conceito de "apropriação" (2006, p. 79). Isso mostra um olhar para o livro didático e, especialmente, para o saber escolar. Trata-se de considerar que as novas pesquisas sobre o tema estão a favor do "[...] seu exame como um artefato material que encontra utilizações as mais variadas nas práticas educativas e escolares [...]" (MUNAKATA, 2006, p. 79). Significa dizer que, cada vez mais, os pesquisadores têm considerado que existem subjetividades que operam no gesto de leitura desses livros não apenas como receptoras passivas, mas criando diferenças de uso no fazer docente.

A pesquisa que sustenta os dados para esse artigo toma como parte do seu objeto os livros didáticos de História, porém metodologicamente foge das análises de conteúdo e também de apropriação. Desta feita, este artigo trata de parte dos resultados da pesquisa de doutoramento intitulada Discursos educacionais na construção das subjetividades cidadãs e implicações no ensino de História: um jazz possível, que privilegiou a análise do discurso, $\mathrm{AD}$, de corrente francesa, como caminho metodológico ${ }^{1}$. Essa escolha metodológica de leitura considera a tríade sujeito, história e linguagem e seus efeitos interpretativos. Esse caminho possibilitou perceber o funcionamento discursivo das duas coleções de livros didáticos mais escolhidas pelos professores da Rede Municipal de Educação do Município de Itajaí, litoral 
norte de SC, a partir do Guia de Livros Didáticos de 2005: a Coleção Nova História Crítica, de autoria de Mario Furley Schimidt, publicada pela editora Nova Geração, e a Coleção História \& Vida Integrada, de autoria de Nelson Piletti e Claudino Piletti, da editora Ática.

No entanto, como recorte de uma pesquisa mais ampla, este artigo socializa apenas alguns resultados das análises dos discursos dessas duas coleções de livros, sem deixar de considerar o texto como um espaço aberto de leituras na interface com outros contextos de sentidos, especialmente relacionados às orientações dos Parâmetros Curriculares Nacionais, PCNs, e do Programa Nacional do Livro Didático, PNLD. Esse último, em especial, funciona como contexto de produção dos textos dos livros didáticos, uma vez que se trata de uma política estatal que organiza, direciona e avalia todo o processo. Em AD, os discursos consubstanciam a materialidade das intenções dos sujeitos que os elaboram e também dos contextos que os possibilitam. No entanto, a relação entre discurso e contexto de produção, longe de acontecer num sentido unilateral, é considerada dialética na $\mathrm{AD}$, uma vez que tanto "o contexto não restringe simplesmente a linguagem, mas é também um produto de seu uso" (CHARAUDEAU; MAINGUENEAU, 2004, p. 128).

A importância do PNLD é central, uma vez que representa também algo que já foi registrado pela historiadora Circe Bittencourt (2004), que é justamente a "evidência do papel do Estado nas normatizações e controle da produção" (p. 273). Entendido também como mercadoria do campo editorial: um produto cultural marcado pela lógica do mercado, mas que, ao mesmo tempo, exerce seu papel como suporte pedagógico e meio pelo qual os valores e os agenciamentos coletivos de uma cultura se espalham. Um material com esse nível de abrangência em termos de funções sociais não passaria despercebido pela tecnologia de controle do Estado.

Preocupado com a qualidade dos livros didáticos em relação ao agenciamento coletivo relacionado à cidadania, o PNLD prevê parcerias com as universidades públicas e, dessa forma, garante uma avaliação academicamente legitimada e aparentemente "neutra" em relação a ideologias políticas. O uso da expressão "ideologia política”, nesse contexto, não possui relação com a política partidária, mas especialmente com a política de Estado. No entanto, a academia, a produção de conhecimentos, de pesquisa possui, desde sempre, intimidades com esse governo. Não se trata aqui de um sujeito político, ou 
de representantes de um partido X mas, sobretudo, de um caminho para atingir fins políticos. Trata-se de uma ação calculada de forças e relações que atingem a população. E a academia, o local de produção de saberes, é um dos pontos desse cálculo de forças.

O PNLD, a partir dos avaliadores espalhados pelas universidades federais de todo o país, conseguiu ao longo dos anos se valer de uma maquinaria de avaliação da produção editorial capaz de regular os estereótipos, preconceitos que poderiam circular em livros didáticos de História. Após as avaliações por uma equipe academicamente legítima, os livros aprovados são incluídos em um catálogo para o professor escolher a coleção que será utilizada em sua escola nos próximos três anos. Como anunciado no artigo de Miranda e Luca (2004)

\begin{abstract}
Nos vários editais e nos guias publicados, tais critérios têm sido exaustivamente repetidos: existência de erros de informação, conceituais ou de desatualizações graves; veiculação de preconceitos de gênero, condição social ou etnia, bem como de quaisquer formas de proselitismo e, por último, verificação de incoerências metodológicas graves entre a proposta explicitada e aquilo que foi efetivamente realizado ao longo da obra [...] (p. 127).
\end{abstract}

Assim, marcando o lugar de uma "filtragem rigorosa" (BRASIL, 2005, p. 6), o guia apresenta aos professores as resenhas e análises de todos os livros disponíveis à sua escolha. Esse material traz análises dos conteúdos, dos caminhos metodológicos, das posições historiográficas das autorias. E a metodologia traçada pelo PNLD responde a esse objetivo; e o texto do guia funciona para tal objetivo. Esse é o contexto de produção dos livros didáticos, as editoras se filiam a essa política estatal por meio de um edital, sabendo que as coleções serão avaliadas a partir de critérios do Estado democrático brasileiro, ou seja, o "grande discurso" que deve perpassar a educação nacional - a cidadania.

Os jogos discursivos para atender essas exigências foram metodologicamente analisados aqui utilizando das tipologias discursivas que parecem fazem funcionar a grande tipologia do "discurso educacional", cunhado nos documentos e orientações oficiais. Essas tipologias, que receberam o nome de "discurso pedagógico", "discurso histórico" e "discurso imagético", foram criadas durante as análises dos livros. Pautada na AD, de corrente francesa, essa pesquisa concordou com Eni Orlandi quando 
ela diz que "[...] a noção de funcionamento, estendida para o discurso, faz com que não trabalhemos apenas com o que as partes significam, mas que procuremos "quais são as regras que tornam possível qualquer parte [...]" (2002, p. 80).

Não interessaram nem os aspectos formais da língua, nem os conteúdos da História, mas, como os autores e editoras fizeram funcionar sentidos de sedução, de prescrição, de conhecimentos da histórica e, ainda, posicionamentos políticos em um mesmo material. Buscou-se perceber as regras dos textos. Este trabalho privilegia essa dimensão mais pragmática, que referencia o conhecimento linguístico junto ao conhecimento das relações sociais, tornando-os híbridos. É a marca histórica da AD. No entanto, a questão aqui apresentada está justamente na fluidez desse lugar praxeológico. Se a dimensão dos usos da língua possui centralidade no interior da AD e se esses usos são diversos como são os contextos sociais, trata-se de um objeto que é furtivo. E exatamente por essa característica que desliza ou escapa aos sentidos, ao analista é exigida a construção de um dispositivo teórico de interpretação para cada objeto a ser analisado. A AD inaugura um tipo de análise que precede a teoria. Para cada discurso que será objeto de análise faz-se necessária uma teorização diferenciada. Não existe uma teoria prévia que se encaixa a todos os discursos produzidos em situações históricas diversas.

É nesse sentido que Eni Orlandi, ao introduzir a segunda edição de sua obra $A$ linguagem e seu funcionamento, adverte que "[...] a cada passo, a AD redimensiona seu objeto, reavalia aspectos teóricos e se relaciona criticamente com seu(s) método(s) [...]" (2003, p. 11). A analista do discurso afirma, na obra $A$ inquietação do discurso, organizada por Denise Maldidier, que o exercício de ver a funcionalidade do texto é uma

[...] tarefa ainda mais difícil quando se trata de uma ciência como a análise de discurso, em que a análise precede, em sua constituição, a própria teoria. Ou seja, é porque o analista tem um objeto a ser analisado que a teoria vai-se impondo [...] (2003, p. 10).

Dessa forma, não existe uma teoria que possa contemplar todos os possíveis funcionamentos de um discurso. Esta análise, então, é um exercício de fazer ver algumas tipologias que operam no funcionamento dos textos dos livros analisados. 
A tipologia educacional no discurso foi definida na análise ressaltando sua característica sedutora e prescritiva. São características dos discursos que fazem funcionar sentidos nos textos. Aqui foi verificado o esforço para o discurso educacional se manter sedutor, quando necessário, e, ao mesmo tempo, prescritivo. E, outra vez, ele se mostrou com característica híbrida. Dessa feita, classificá-lo como isso ou aquilo pode ser um equívoco ou um caminho empobrecedor. A tipologia educacional permite que ora o discurso se apresente com um perfil, ora com outro. Nessa análise específica, ele transitou pelos discursos "histórico", "pedagógico" e "imagético".

A construção de categoria de análise a partir de tipologias discursivas é sugerida pela analista de discursos Eni Orlandi e se funda a partir de características pelas quais se localiza o funcionamento discursivo. São tipos de discurso que revelam as intenções da fala e a forma como esse discurso se organiza para cumprir suas intenções. No caso dos livros didáticos de História, o uso das tipologias é uma espécie de "dança híbrida", porque além do local da ciência de referência História, o livro precisa fazer funcionar, também, uma lógica pedagógica, além de tornar-se sedutor para o público de leitores adolescentes. O jogo da linguagem precisa respeitar algumas regras que estão na tipologia pedagógica, nas prescrições e na responsabilidade com o ensino da História e, ao mesmo tempo, na polissemia e provisoriedade orientadas pelo discurso da História, sem deixar perder-se a sedução orientada pela indústria editorial, afinal, o livro precisa funcionar, também, como objeto de desejo para um consumo.

O discurso pedagógico analisado por Eni Orlandi nos livros didáticos possibilitou a ela verificar as tipologias do "discurso autoritário" ou do "discurso polêmico" (ORLANDI, 2003). Essa pesquisa considerou e concordou com esses estudos já desenvolvidos por Orlandi e ampliou as relações dele, as tipologias historiográficas e imagéticas. Como dito anteriormente, este artigo é parte de uma pesquisa maior onde foi analisada uma maior quantidade de texto das coleções, porém, para esse artigo o recorte privilegiou partes da análise onde essas tipologias foram percebidas de forma mais evidente. Desta feita, da Coleção Nova História Crítica foi analisado o capítulo 14 do livro da $7^{\mathrm{a}}$ série e, na Coleção História \& Vida Integrada, optou-se por abalisar o capítulo 1 do livro da $6^{a}$ série. Nas duas coleções, a análise seguiu a organização de leitura dos autores, a sequência de exposição dos textos, os boxes, as atividades e propostas. Na primeira 
coleção, o destaque da análise foi o sentido de sedução e prescrição dos discursos e, na segunda, o discurso didático e os sentidos do "politicamente correto" a partir do uso das tipologias citadas, ambos muito evidentes nos capítulos escolhidos.

\section{AS TIPOLOGIAS DA COLEĈ̣̃O NOVA HISTÓRIA CRÍTICA}

O três discursos - pedagógico, historiográfico e imagético - parecem óbvios, já que se trata de um livro didático de História que, por sua vez, apresenta imagens. Porém, não se trata aqui dessa obviedade, mas de como essas três tipologias discursivas são dispostas a serviço de manter a tipologia educacional sedutora e prescritiva ao mesmo tempo.

A sedução dos discursos dos livros da coleção é explícita. Ela é revertida no número de professores que a escolhem, apesar das críticas apresentadas no Guia do Livro Didático de 2005, e, nesse sentido, ela atende, também, uma demanda mercadológica. Na cidade de Itajaí, SC, a coleção está entre as mais escolhidas, e não é um caso isolado². Onde está essa sedução?

Nas primeiras páginas do livro, o texto é especialmente escrito, diagramado, pensado para seduzir. As letras são coloridas, o texto direcionado com intimidade ao "amigo leitor". Parece uma conversa entre amigos. Como no exemplo: "É legal ter uma visão global antes de se aprofundar nos detalhes". Dizer "é legal" em troca de "consideramos pedagogicamente necessário ou importante" funciona de forma diferente diante do público leitor. Esse texto introdutório também diz que as ilustrações, gráficos, tabelas não são enfeites, "para ficar bonitinho", mas que precisam ser lidos, investigados. Mas, ao dizer o que esses recursos não são, o texto os destaca logo na primeira página.

Voltando ao jogo de sedução e prescrição do livro, no entanto, o outro lado do discurso educacional - a prescrição - se faz predominante. Muito embora o texto introdutório diga ao aluno que o livro apresenta uma versão da História e que é preciso questioná-la, como na afirmação:

"Quando você ler um livro didático, pode ter certeza de que ele poderia ter sido escrito de outra maneira, tão válida como esta. Por isso, nunca se esqueça de que duvidar e questionar são atividades muito saudáveis." (SCHIMIDT, 2002, p. 07). 
A forma como os discursos são dispostos no desenvolvimento dos conteúdos pouco oferece para a operação desses questionamentos.

A organização didática da coleção é um exemplo dessa limitação para a construção da ideia do fazer histórico. Os capítulos fazem o seguinte movimento: 1) apresentação de um resumo do capítulo, as ideias principais que serão trabalhadas naquele capítulo; 2) desenvolvimento dos assuntos; 2.1) ilustrações, tabelas, gráficos e mapas que dão suporte ao texto e ao desenvolvimento dos assuntos; 3) seção chamada Texto Complementar, que apresenta um trecho de um texto da historiografia; 3.1) reflexões sobre o texto complementar; 4) sequência de atividades chamadas Exercícios de revisão, que abordam os assuntos trabalhados no capítulo; 5) atividade chamada Reflexões críticas, que traz um tema contemporâneo relacionado a assuntos trabalhados no capítulo.

Aqui, o discurso pedagógico direciona o movimento de leitura. Uma breve apresentação do tema, uma versão sobre aquela História, mapas, fontes, imagens, gráficos que confirmam o texto escrito, uma fonte da historiografia que reforça o argumento, seguidos das atividades. O texto, nessa organização didática, não consegue operar na lógica da construção de um conhecimento histórico. $\mathrm{O}$ autor oferece sua versão sobre a História e depois atividades de revisão e reflexão, ou seja, a ação do aluno, além da leitura, possui como base aquilo que ele já leu. São respostas àquela única versão da História. Apesar de o autor afirmar no texto introdutório que sua intenção é que o leitor critique, duvide, pergunte, a condução de suas ações, no decorrer dos capítulos, não permite esse movimento. O discurso pedagógico formata o historiográfico e torna o movimento de leitura autoritário.

Essa afirmação advém das análises desenvolvidas por Eni Orlandi. Ao analisar o discurso pedagógico, ela o classifica como autoritário a partir de três tipos discursivos: o lúdico, o polêmico e o autoritário. O critério dessa classificação foi o grau permitido para a polissemia. Segundo a autora, o discurso lúdico possui o objeto do que se fala presente entre os interlocutores e esses são livres para exporem interpretações numa polissemia aberta. Não há mediação nessas interpretações. Diferente do discurso polêmico, em que o objeto também está presente entre os interlocutores mas esses não se expõem livremente, ao contrário, "procuram dominar o seu referente" (ORLANDI, 2003, p. 15), ou seja, há interpretações várias sobre o objeto de 
que se fala, por isso, polêmica, mas, mediante um controle, os interlocutores falam a partir de parâmetros e critérios. E, finalmente, no tipo autoritário, o objeto, o referente do que se fala está ausente, não há interlocutores, mas um sujeito exclusivo para falar sobre aquele referente e, daí, uma polissemia contida. Para explicar melhor o terceiro tipo discursivo, Eni Orlandi apresenta as formações imaginárias dessas interlocuções a partir da seguinte frase: "Quem ensina o quê, para quem, onde" (ORLANDI, 2003, p. 16). "Quem" é a imagem do professor; "ensina" ela relaciona com "inculca"; "o quê" é a imagem do referente (porque o objeto em si está ausente, o que temos é a metalinguagem da ciência, um fato convencionado); "para quem" é a imagem do aluno; "onde", na escola, que ela chama de "aparelho ideológico".

Dessa forma, o sujeito que fala sobre um objeto ausente, convencionado sob um discurso, é aquele que possui a investidura para falar sobre essa convenção. E o aluno é o receptor desses discursos e, por isso, não possui um conhecimento sobre o objeto ausente para falar sobre ele e promover uma polêmica. Ao observar o movimento que o discurso pedagógico promove quando organiza o discurso historiográfico, é exatamente essa formação imaginária que ele considera. Quando o autor apresenta a coleção para o leitor, promete um tipo de discurso polêmico. Em outras palavras, ele diz: "vou apresentar uma versão sobre o fato histórico, mas essa versão não é única e você pode e deve discordar de mim”. Mas, quanto às possibilidades que oferece, ele também diz: "discorde de mim, mas faça isso sozinho, você consegue".

$\mathrm{O}$ autor reserva para o aluno três momentos de atividade, além da leitura: 1) as reflexões sobre o texto complementar; 2) os exercícios de revisão; e 3) as reflexões críticas. $\mathrm{O}$ ato de raciocinar historicamente aparece nos três momentos e algumas frases podem exemplificar o que se espera das ações dos leitores:

1) Será importante você relacionar essas informações com o que já aprendeu no texto principal; Por intermédio deles [dos textos complementares], você pode construir seu conhecimento;

2) Perguntas que você sempre deve formular para compreender um processo histórico: quais foram as causas? $\mathrm{E}$ as consequências? Como as coisas se relacionam? 
3) A resposta deve ser encontrada por você mesmo, com sua inteligência, seus conhecimentos, sua experiência, na troca de ideias com seus colegas (SCHIMIDT, 2002, p. 08).

Observa-se que quando o autor organiza seu texto pedagogicamente, escolhendo deixar as atividades, os questionamentos para o final do capítulo, ele está dizendo para o leitor: "pode discordar das minhas ideias, mas eu não estou mais aqui", ou seja, o discurso está longe de ser polêmico.

A análise dessas frases nos permite interpretações variadas, mas aqui podemos destacar algumas relacionadas ao pensar historicamente. Considerando o movimento pedagógico no qual o autor organiza seu texto, parece possível interpretar que ele assume uma postura de conhecedor e ensinador da História. E, nesse sentido, seu texto oferece mais conteúdos factuais do que conceituais ou procedimentais e apenas nos finais dos capítulos ele convoca o leitor para assumir os conteúdos atitudinais. Esse conjunto de frases são convites e ou regras que devem orientar essas atitudes.

Nesse momento, o autor recua, supõe-se que o professor assuma a mediação e os alunos sejam autoaprendizes. Frases como "você pode construir seu conhecimento", "perguntas que você deve formular", "‘ resposta deve ser encontrada por você mesmo" revelam que a autogestão está imbricada na proposta do autor, embora ela não esteja assumida. A análise discursiva do texto do capítulo 14 do livro da $7^{\mathrm{a}}$ série é exemplo dessa postura do autor como professor. Com o título Doutrinas sociais, o autor inicia explorando o discurso imagético na introdução do capítulo. Uma imagem da famosa pintura de Volpedo, 1905, ilustra a página. As letras são coloridas e o título parece saltar sob um buraco de uma página queimada e envelhecida (Figura 1).

Ele inicia, seguindo as orientações didáticas dos PCNs: "[...] questionar os alunos sobre o que sabem, quais suas idéias, opiniões, dúvidas e/ou hipóteses sobre o tema em debate e valorizar seus conhecimentos [...]" (BRASIL, 1998, p. 77). "Por que existe a pobreza e a violência? Seria possível superar os problemas sociais?" Em seguida, já começa a esboçar respostas: "No século XIX, surgiram doutrinas políticas que propunham a reorganização da sociedade" (SCHIMID'T, 2002, p. 200). E segue delineando o que será 


\section{Figura 1}

Doutrinas sociais - pintura de Volpedo, 1905.

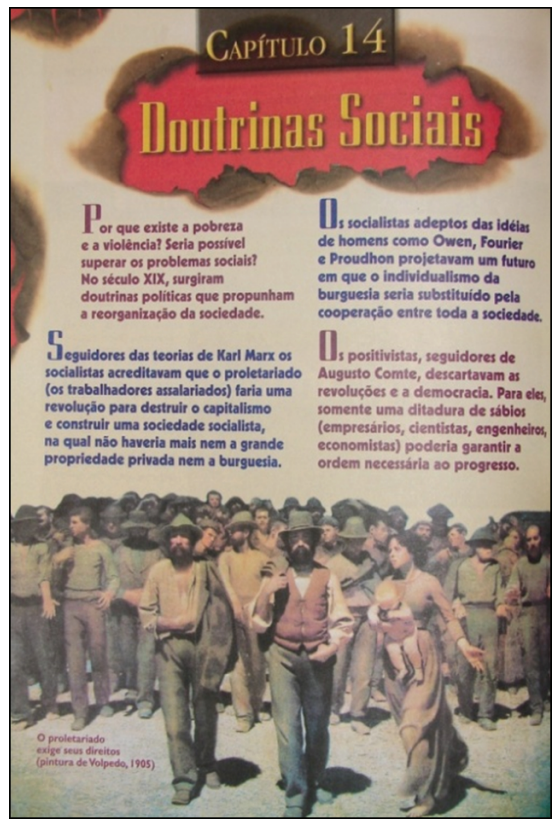

Fonte: Coleção Nova História Crítica, livro da $7^{\mathrm{a}}$ série, p. 200. São Paulo: Nova Geração, 2002.

explorado no capítulo: as ideias de Karl Marx, Owen, Fourier, Proudhon e Augusto Comte. Na página seguinte, volta às perguntas iniciais sugeridas pelos PCNs. Essas perguntas trazem situações da realidade contemporânea. São algumas delas:

Você já reparou que vivemos numa sociedade cheia de desigualdades? Por que uns são ricos e outros são pobres? Por que uns são bem alimentados e podem estudar até a universidade enquanto outros devem procurar emprego desde cedo? Por que existem diferenças sociais?" Investido de uma fala de professor, o autor inicia a sua aula expositiva: "Há séculos que a humanidade tem feito essas mesmas perguntas. Muitas respostas diferentes já foram dadas. Será que a solução poderá ser encontrada no século XXI?. (SCHIMIDT, 2002, p. 201).

Em seguida, o autor escreve sobre os primeiros socialistas e o que separa o primeiro texto do segundo são duas imagens. A primeira é a foto de um mendigo norte-americano oferecendo trabalho em troca de comida. 
A segunda, uma pintura de 1873, retrata alguns miseráveis russos pedindo esmola a um casal burguês (Figura 2 e 3 ).

Aqui fica claro o local de crítica ao capitalismo. As legendas das fotos dizem:

\section{Figura 2}

Relações temporais e espaciais diferentes sobre a miséria.

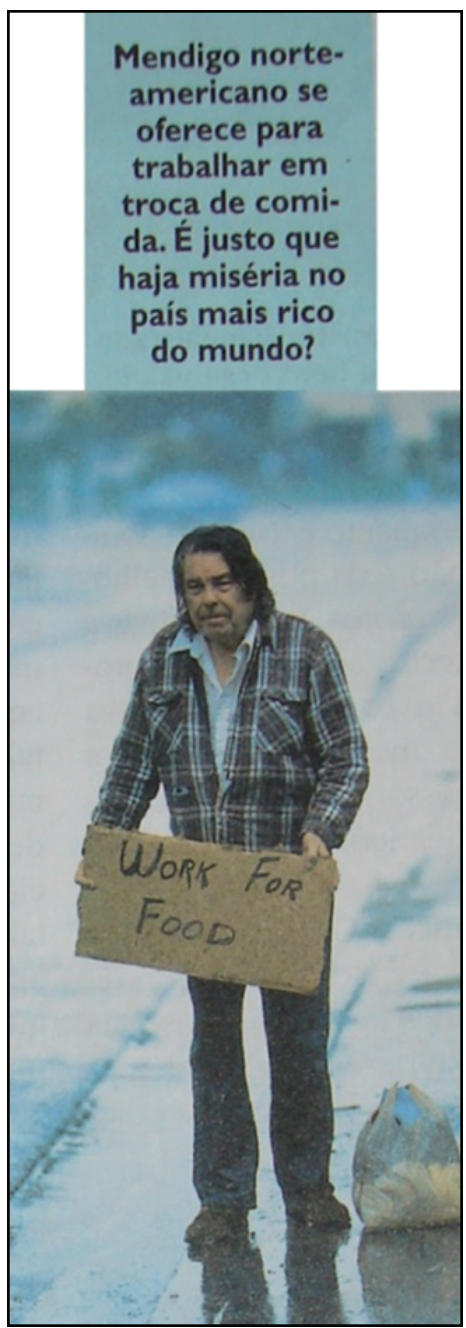

Fonte: Coleção Nova História Crítica, livro da $7^{\mathrm{a}}$ série, p. 201. São Paulo: Nova Geração, 2002. 


\section{Figura 3}

Relações temporais e espaciais diferentes sobre a miséria.

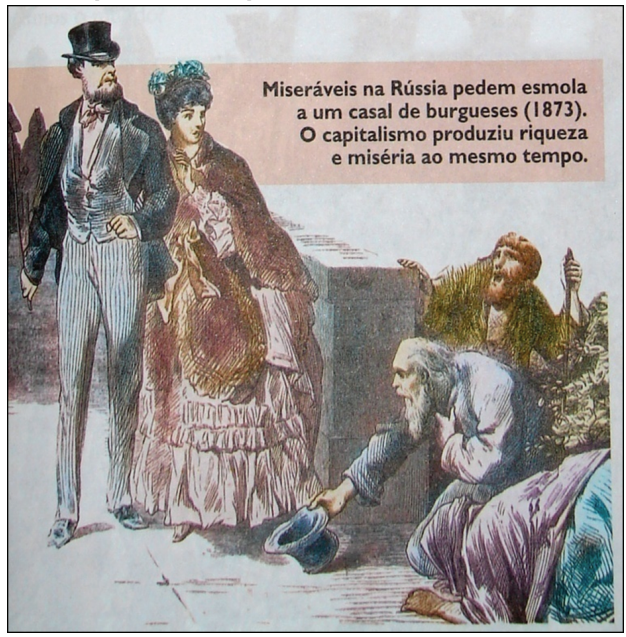

Fonte: Coleção Nova História Crítica, livro da $7^{\text {a }}$ série, p. 201. São Paulo: Nova Geração, 2002.

Mendigo norte-americano se oferece para trabalhar em troca de comida. É justo que haja miséria no país mais rico do mundo?

Miseráveis na Rússia pedem esmola a um casal de burgueses (1873). O capitalismo produziu riqueza e miséria ao mesmo tempo (SCHIMIDT, 2002, p. 201).

A legenda da segunda imagem teria outro sentido sem a data, mas ela fala sobre a situação russa antes da revolução e contrasta com a imagem atual nos EUA. O desenvolvimento do capítulo continua e as imagens reforçam e/ou ilustram o discurso do autor. Continuando, ele apresenta o chamado "socialismo utópico" e, nesse momento, além da crítica ao socialismo, existe claramente sua filiação de sentidos. Ele pergunta:

"Não será tão ruim assim ser utópico? Será que a utopia não é um pensamento vigoroso porque se recusa a aceitar o mundo do jeito que ele é? Será que a utopia não é o grande incentivo para transformarmos o mundo?" (SCHIMIDT, 2002, p. 201).

Ao elaborar a pergunta dessa forma, ela passa a funcionar como uma afirmação. Ela transforma a dúvida em um fim afirmativo. "Não será tão ruim assim ser utópico.” O efeito da pergunta é prescritivo. Em seguida, 
ele não pergunta a característica de um pensamento utópico, afirma ser o pensamento utópico vigoroso e explica o porquê. Por outro lado, na mesma página dá destaque para o socialismo pensado a partir da razão, tanto por Marx e Engels quanto por Charles Fourier. E, na página seguinte, apresenta o capitalismo. Mas a partir de sua leitura de Marx e Engels, ou seja, continua falando a partir do socialismo e as imagens continuam reforçando o local de fala. A estratégia da pergunta, que funciona como afirmação, também continua.

Abaixo, segue um texto com o título A irracionalidade do capitalismo que se constitui como um conjunto de perguntas afirmativas. É importante ressaltar que os textos anteriores falaram sobre um socialismo racional, científico e, em seguida a palavra "irracionalidade" funciona como exclusão do pensamento capitalista no meio científico. $O$ texto não apresenta nenhum pensador que tenha argumentado o capitalismo sob o viés científico. Ao contrário, ele cita Marx e Engels para explicar o socialismo e também para desclassificar o capitalismo. O aluno recebe, nesse capítulo, apenas um ponto de vista sobre o que o autor chama de "doutrinas sociais". Voltando às ideias da analista de discursos Eni Orlandi, tanto o texto de Marx e Engels quanto o socialismo ou o capitalismo estão ausentes, aqui se tem a leitura do autor e aquilo que na ideia dos autores ficou convencionado falar. O referente está ausente; tem-se a imagem que o autor construiu sobre o referente. Apenas uma imagem sobre o referente: a do autor. As fotos, charges, imagens não são fontes históricas que tragam polêmica, ou que ofereçam outras versões sobre o mesmo referente; são apenas confirmações do mesmo discurso.

E após esse texto sobre a "irracionalidade do capitalismo" segue-se outro com as mesmas características, explicando como aconteceria o fim da propriedade privada. Mas como funciona esse discurso? As perguntas que o autor faz, como dito anteriormente, não funcionam como perguntas; elas, efetivamente, afirmam: “é ou não absurdo...”. O autor já diz que é um absurdo. Antes de começar as perguntas, ele propõe: "Veja e decida você mesmo", mas após as perguntas, sem possibilidade de decidir, o leitor depara-se com a seguinte afirmação: "Para Marx e Engels, a resposta seria única: o capitalismo é totalmente ilógico". O autor afirma, mas sob a voz legítima daqueles que ele apresentou anteriormente como "intelectuais" (SCHIMIDT, 2002, p. 203). 
Seguindo a ideia da formação imaginária proposta por Eni, existe nesse discurso, apesar dos pontos de interrogação, a ausência de funcionamento polêmico. O que funciona nele é, pois, uma tipologia autoritária. Na página seguinte, um discurso imagético reforça a mesma tipologia (Figura 4).

\section{Figura 4}

\section{Uso de charges no livro didático Nova História Crítica - doutrinas sociais. São Paulo: Nova Geração, 2002.}

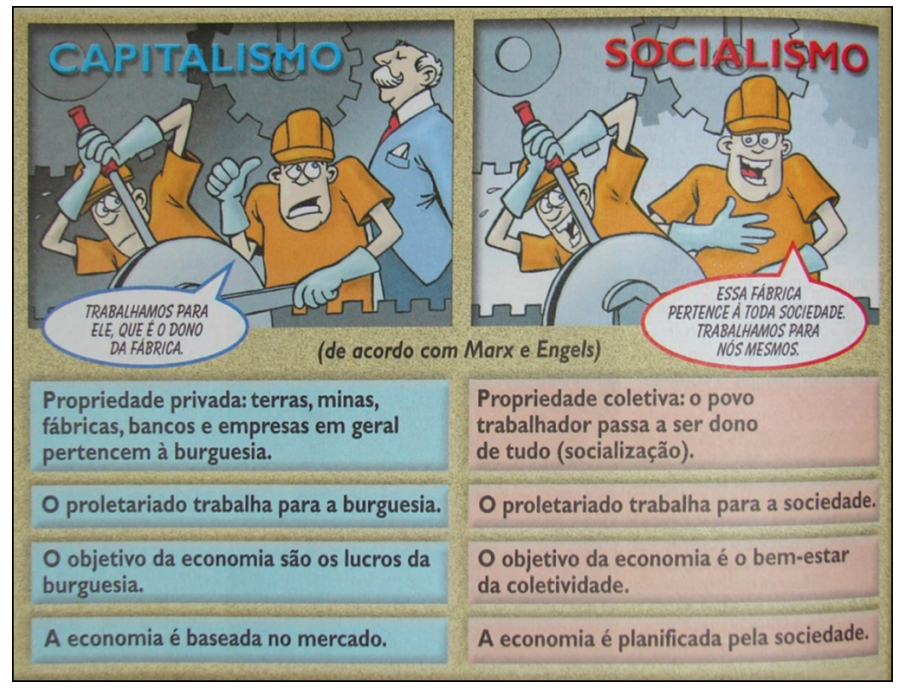

A charge propõe o que ele chama de "doutrinas sociais": o capitalismo e o socialismo. Ambos sob a imagem do que seriam o marxismo e engelismo. De um lado, dois operários trabalhando, tendo ao fundo um patrão. Os dois estão vestidos com macacões e capacetes de cor laranja e o patrão com terno cinza, sóbrio, e gravata vermelha, investido de poder. $\mathrm{O}$ rosto dos operários expressa opressão e medo, e um diz: "trabalhamos para ele que é o dono da fábrica". No quadro ao lado, os dois operários estão na mesma posição, com a mesma roupa, mas sem o patrão atrás e com a expressão de alegria e dizem a seguinte frase: "essa fábrica pertence a toda sociedade, trabalhamos para nós mesmos". As expressões de opressão e de felicidade dos dois operários reforçam as afirmações em forma de perguntas apresentadas no texto A irracionalidade do capitalismo. 
O autor segue o capítulo utilizando a mesma estratégia de escrita. Seduz com as imagens ou quando se apresenta no local da crítica e, ao mesmo tempo, prescreve como se estivesse dando uma aula expositiva. Pergunta afirmando e não operacionaliza a construção do conhecimento histórico enquanto ação do leitor. Apenas ao final do desenvolvimento dos assuntos oferece o espaço de ação do leitor. Continuando o exemplo do capítulo 14 do livro da $7^{\mathrm{a}}$ série, ele segue com um movimento confirmador dos textos propostos anteriormente. No box intitulado Texto Complementar, o autor escreve:

Em 1848 estourou a primeira crise da história do capitalismo. A miséria dos trabalhadores e a revolta social cresceram. No mesmo ano, Marx e Engels lançaram um livrinho chamado Manifesto do Partido Comunista, que continha um resumo das ideias do socialismo científico. Vejamos uma parte dessa célebre obra (SCHIMIDT, 2002, p. 204).

Após esse enunciado apresenta trechos recortados da obra, frases coladas com parênteses e reticências que marcam o trabalho de bricolagem proposital do autor. Ou seja, o enunciado remete ao mesmo local de fala em que é desenvolvido o capítulo. É uma fonte histórica que funciona para confirmar seu discurso. Perguntas seguem os trechos recortados. Ele diz:

A partir do que é apresentado pelos autores do texto acima, procure responder:

1. Marx e Engels consideram que a História é baseada em conflitos sociais. Que conflitos são esses?

2. Por que eles acham que a burguesia teve um papel revolucionário na História?

3. Quem seriam os coveiros da burguesia?

4. Por que o crescimento da economia capitalista condenaria a burguesia? (SCHIMIDT, 2002, p. 204).

As expressões o quê, por quê e quem exigem respostas recortadas, fechadas. Elas estão no texto e provocam uma interpretação dirigida. Igualmente nos Exercícios de Revisão, porém um pouco mais abertas, as perguntas exigem nada mais que uma confirmação sobre o ponto de vista apresentado no decorrer do capítulo. Não existe aqui um julgamento sobre a importância ou não de atividades dessa natureza, contudo, interessa para 
esta análise perceber onde está o movimento de pensar historicamente prometido pelo autor na apresentação da coleção e onde são respondidas as expectativas do Estado em relação àquilo que a consciência histórica pode promover - a identidade cidadã, o pertencimento ao Estado democrático. O funcionamento do texto não permitiu o pensar historicamente.

Os exercícios de revisão são organizados em nove perguntas. Dessas nove, cinco são construídas seguindo a lógica do texto complementar: um pequeno trecho de autor, já trabalhado no capítulo, e uma pergunta interpretativa. Das quatro perguntas restantes, três referem-se a Marx e Engels: "Para Marx e Engels, qual seria [...]", "Para Marx e Engels, por que o proletariado [...]" e, ainda, "Explique as duas críticas básicas que Marx e Engels faziam ao [...]"(SCHIMIDT, 2002, p. 217). Apenas em uma questão o aluno sai do movimento interpretativo e pode relacionar dois acontecimentos diferentes: "Explique as principais diferenças entre as sociedades tradicionais e as sociedades modernas"(SCHIMIDT, 2002, p. 217).

As atividades chamadas Reflexões Críticas são apresentadas com um texto mais aberto e possibilitam mais a ação do leitor. Porém, o local do autor ainda aparece direcionando algumas ações. Essas atividades estão organizadas em 11 questões mas, antes delas, duas imagens retratam a diferença social norte-americana. Um homem negro sob um barraco de papelão na rua e uma mansão ao estilo dos filmes de Hollywood. Essas duas imagens são propositais nesse momento. As diferenças de classes poderiam ser ilustradas com imagens de qualquer parte do mundo, mas esse capítulo, chamado pelo autor Doutrinas Sociais, aciona memórias relacionadas à Guerra Fria, aos dois grandes polos mundiais, e o local de fala do autor destaca, nesse momento, a crítica ao capitalismo.

As imagens, seguidas de legenda, mostrando um grave problema social nos EUA - no considerado maior país democrático, ou o país mais rico do mundo -, são, no mínimo, denunciadoras. E as questões seguem provocando o reforço dessa crítica. Todavia, a linguagem utilizada por vezes permite o olhar diferenciado. A primeira questão que segue as imagens propõe:

Há pessoas que alegam que jamais será possível existir uma sociedade comunista porque o egoísmo faz parte da natureza humana: sempre haverá pessoas com ambições, querendo ficar acima das outras. Além disso, as pessoas são diferentes, nunca haverá total igualdade. Os marxistas discordam e argumentam que 
não existe uma natureza humana imutável: a sociedade comunista educaria os homens e as mulheres para viverem em harmonia. Dizem também que na selva capitalista o egoísmo é uma estratégia de sobrevivência, mas na nova sociedade, igualitária e livre, a decisão mais racional seria a cooperação. O que o amigo leitor pensa a respeito? Apresente seus argumentos! (SCHIMIDT, 2002 , p. 205, grifo meu).

Observa-se que quando fala sobre um argumento a favor do capitalismo, não existe sujeito definido na frase. "Há pessoas", elas existem, estão por aí, mas não possuem um rosto. Existe um descrédito para essa ideia. Assim como foi apresentado no capítulo, não houve citação de nenhum autor que tenha pensado o capitalismo cientificamente a não ser os próprios Marx e Engels, para dizer que era um pensamento irracional. Aqui isso se repete de outra forma: "pessoas" defendem o capitalismo. Já a argumentação contra a competição, o egoísmo, são os "marxistas" quem fazem. São sujeitos que possuem um perfil, são filiados às leituras de Marx, possuem uma defesa científica, legitimada. Em seguida, a chamada: e você "amigo leitor?" Aqui também existe um sujeito da ação. Alguém que não vai ficar parado, é preciso decidir de que lado vai estar: daqueles que não têm perfil ou junto daqueles que sonham e pensam racionalmente? Mesmo que a questão seja aberta, quando diz: "Apresente seus argumentos!", a possibilidade de construir uma argumentação foi direcionada durante todo o capítulo.

Outra questão que se propõe aberta mas ardilosamente faz um movimento agenciador de sentidos possui os seguintes dizeres: “Qual tipo de sociedade é mais compatível com os valores religiosos que você defende: a capitalista ou a socialista? Ou será que tanto faz?" A pergunta final "ou será que tanto faz" abre para sentidos outros que o leitor pode construir. Porém, até aqui, já foram muito lidos discursos como "egoísmo", "opressão", "guerra", "luxo" relacionados ao capitalismo - que acionam memória dos sete pecados capitais - e "igualdade", "fraternidade", "solidariedade", relacionados ao socialismo - virtudes religiosas. Mesmo sabendo que as chamadas "doutrinas sociais", especificamente o socialismo, o capitalismo e o positivismo, podem ser adaptadas às doutrinas cristãs - a história nos mostra essas adaptações quando houve necessidade de conivência nas relações sociais de poder -, neste capítulo o discurso desenvolvido relaciona diretamente as virtudes religiosas às ideias socialistas. Para o leitor que 
permaneceu passivo até aqui será difícil elaborar um argumento para a provocação: "Ou será que tanto faz?"

Nesse sentido, o discurso da coleção foi classificado na tipologia educacional. Ele transita em diversos discursos, pedagógicos, históricos, imagéticos, consegue ser sedutor e prescritivo ao mesmo tempo. Para os desavisados, pode estar em consonância com os agenciamentos coletivos propostos pelo Estado brasileiro mas, ao analisar seu discurso mais de perto, observam-se dissonâncias permitidas pela natureza do sistema democrático e outras que impedem o texto de funcionar como didaticamente se propõem os discursos pedagógicos. O funcionamento do discurso da coleção opera contrariando o texto de apresentação do autor, que não se propõe a fazer com que o aluno decore datas e fatos, contrariando também a sequência de atividades que não propõem o apontamento desses marcos históricos, didaticamente o discurso da coleção funciona como um conjunto de "bens culturais da humanidade", contados pela óptica ou recortes, bricolagens do autor, que favorecem um conhecimento entendido como acúmulo de saberes que são avaliados ao final de cada etapa.

\section{AS TIPOLOGIAS DA COLEĈ̣̃O HISTÓRIA \& VIDA INTEGRADA}

O discurso da coleção História \& Vida Integrada, de autoria de Nelson Piletti e Claudino Piletti, editora Ática, é marcado pela didática. Sua análise também foi feita a partir da tipologia educacional, um híbrido entre as tipologias pedagógica, histórica e imagética, sempre funcionando como sedução e prescrição. Porém, na forma como o texto vai desenvolvendo os assuntos propostos em cada capítulo, é o discurso da ciência pedagógica que prevalece: a didática orienta o que é recortado, desenhado. É ela que atravessa a fala dos autores em destaque no discurso. Essa organização didática se materializa no texto da seguinte forma: os autores fazem uma pequena introdução dos assuntos que serão tratados no capítulo, em seguida iniciam o desenvolvimento e ao mesmo tempo abrem pequenos boxes intitulados A História em Debate, onde apresentam informações atuais sobre temáticas que estão sendo trabalhadas. Esse box pode aparecer em diferentes momentos do texto e trazer também atividades que o leitor pode fazer durante os estudos do capítulo. Ainda em meio ao texto do desenvolvimento do capítulo 
aparecem outros boxes de fontes históricas, ou adaptações e/ou trechos da historiografia, mapas e imagens que possibilitam confirmar o texto do autor ou ampliar sua fala. Esses mapas ou imagens possuem indicações no próprio texto, com uma linha colorida. Em seguida, as atividades são dispostas, também em boxes. O primeiro, intitulado Discutindo o capítulo, provoca ações no aluno relacionadas à interpretação, associação de ideias, relação e comparação de conteúdos. O segundo box, conforme o título Oficina da História, oferece uma fonte histórica e a partir dela desenvolve conteúdos procedimentais da disciplina. O terceiro, Fazendo a síntese, refere-se à síntese do que foi trabalhado no capítulo e, por fim, Textos e contextos e Nosso mundo hoje propõem situações para pensar a contemporaneidade em relação ao passado. Todas as fontes históricas utilizadas possuem suas citações e legendas imediatamente abaixo e apenas o glossário e bibliografias constam ao final de cada livro.

Existe na coleção uma marcação pedagógica clara. Isso possibilita um pequeno ensaio construtivista para o leitor, ou seja, a forma como estão organizados os boxes oferece condições para um movimento de construção de narrativas históricas. $\mathrm{O}$ texto questiona pouco, ou quase nada, a provisoriedade da História, mas oferece a possibilidade da operação dessa provisoriedade. Às vezes, as fontes históricas aparecem como parte da argumentação dos autores; mas, também, em outros momentos, oferecem pedagogicamente caminhos para além da interpretação, reflexão, comparação, relação, análise e síntese. Os conteúdos são apresentados em consonância com as orientações dos PCNs, exploram os conceitos históricos, os fatos, os procedimentos e as atitudes.

Para exemplificar esse movimento dos autores, a análise do discurso do primeiro capítulo do livro da $\sigma^{a}$ série parece providencial. Os autores apresentam os assuntos que serão trabalhados no capítulo com o seguinte texto:

Quem ainda não ouviu história de cavaleiros, princesas, castelos e florestas encantadas por fadas, magos e feiticeiras? Em sua grande maioria, o cenário dessas histórias é a região que hoje chamamos de Europa ocidental entre os séculos V e XV. Esse será também o cenário dos primeiros capítulos deste livro.

Essa época da história européia é chamada de Idade Média. Os historiadores consideram seu marco inicial a desagregação do Império Romano do Ocidente e a ocupação de suas terras por diversos povos de origem germânica. Os marcos 
finais desse período são a conquista do Império Bizantino pelos turcos e a chegada dos europeus à América, durante o período das Grandes Navegações.

Entre esses marcos passaram-se cerca de mil anos. Foi um tempo em que a maioria das pessoas vivia no campo, restritas a propriedades que buscavam sua autossuficiência.

[...] Muitos estudiosos acabaram chamando esses mil anos de história européia de Idade das Trevas. Eles acreditavam que o misticismo religioso do mundo medieval tinha soterrado o conhecimento produzido por gregos e romanos.

O certo é que durante esses mil anos a sociedade européia construiu grande parte dos valores culturais que iriam se espalhar por todo o mundo a partir das Grandes Navegações (PILET'TI; PILETTTI, 2002, p. 9).

Existe intencionalidade didática nessa apresentação. Observa-se que a localização temporal e espacial aparece logo no primeiro parágrafo do texto. Mas não é uma localização qualquer, os autores se utilizam dos contos de fadas para atrair o leitor. Em outras palavras, eles dizem "é sobre aquelas histórias, que toda criança gosta de ouvir, que vamos falar agora. Se não as mesmas histórias, acontecidas no mesmo lugar e na mesma época”. Eles enquadram no tempo e no espaço aqueles famosos inícios "há muito tempo atrás", ou "era uma vez" ou, ainda, "em um reino muito distante", ou seja, em um tempo mítico.

Em seguida, vão marcando com proximidade os assuntos que serão trabalhados: Idade Média, Império Romano do Ocidente, ocupação dos povos germânicos, Império Bizantino, chegada na América, poder da Igreja, poder político descentralizado, Idade das Trevas, valores culturais, Grandes Navegações. Ao escreverem Idade das Trevas tiveram o cuidado de grifar em outra cor, sinalizar uma linha até o box História em Debate, ao lado. Mesmo ainda não iniciando o desenvolvimento do capítulo, os autores já convidaram o leitor a uma ação além da leitura. A sedução do primeiro parágrafo, de relacionar-se às histórias encantadas, continua. Os autores discursam um pouco mais sobre a chamada Idade das Trevas e propõem:

Nos próximos capítulos, iremos conhecer a sociedade medieval européia e, também, a do Renascimento. Você poderá então chegar às suas próprias conclusões sobre os significados da Idade Média.

Mas antes de começar reúna-se com alguns colegas e façam uma relação das histórias conhecidas por vocês em que estejam presentes castelos, príncipes, 
cavaleiros, donzelas, dragões etc. Depois façam um quadro agrupando os personagens dessas histórias conforme a condição social de cada um. Coloquem, por exemplo, os príncipes de um lado e os camponeses de outro. Depois façam um texto descrevendo cada um desses grupos (PILETTI; PILETTI, 2002, p. 9).

Observa-se que não existe uma intenção conceitual nem factual nessa atividade, apenas procedimental. Os autores não direcionam nem um caminho para interpretar as possíveis representações nos contos de fadas. A atividade é recortada exclusivamente para os conteúdos procedimentais da História: localizar temporalmente, coletar dados, selecionar e organizar os dados, descrever informações.

Continuando a apresentação do capítulo, ao dizer valores culturais os autores utilizam a mesma estratégia pedagógica: sinalizam com cores diferentes, traçam linhas, agora até uma imagem sacra, e completam a ideia com a legenda da foto. Aqui a fonte histórica ocupa uma função ilustrativa e confirmativa do texto do autor. Ou seja, existem, em apenas uma página, três discursos diferentes: o historiográfico, o imagético e, principalmente, o pedagógico, que organiza os dois primeiros.

Em seguida, os autores começam a desenvolver os assuntos propostos. E, nesse exemplo, o que parece ser detalhe não dá pistas de ser ingênuo. Ao tratar da fragmentação do Império Romano, eles dizem:

O poder centralizado do Império Romano começava, assim, a se fragmentar. Em 476, os hérulos, povo de origem germânica, invadiram Roma e depuseram o imperador. Foi o passo final para a desagregação do Império Romano do Ocidente [...] (PILETTI; PILETTTI, 2002, p. 10).

As palavras Império Romano do Ocidente aparecem grifadas, seguidas com linhas até dois mapas. Um de cada lado das páginas. De um lado, o mapa do Império Romano do Ocidente e, do outro, o mesmo mapa destacando o "território ocupado pelos povos germânicos no século VI”. Seria apenas um detalhe se no segundo mapa não houvesse também sinalização das cidades conhecidas no nosso mundo contemporâneo: Paris, Verona, Gênova, Roma, Nápoles, Barcelona, Marselha, Braga e uma legenda: "Os romanos chamavam todos os povos que habitavam além de suas fronteiras de bárbaros. Isso pelo fato de falarem línguas diferentes e terem costumes muito diversos dos seus". 
Na página anterior, ao dizer Idade das Trevas, abriram um box para deixar claro quem nominou dessa forma o período. Nessa página usam povos germânicos em detrimento de bárbaros, sinalizam o espaço com o nome das cidades tradicionalmente significadas no chamado primeiro mundo e explicam em uma legenda que a palavra bárbaros possui relação com a intolerância com o outro.

Nesse caso, as fontes utilizadas - os mapas - não funcionaram apenas para localizar ou ilustrar a versão dos autores, mas para possibilitar outras leituras não diretas. Existe nesses discursos uma intencionalidade de construção conceitual do politicamente correto. É um direcionamento de interpretação, os signos estão disponíveis mas não são oferecidos explicitamente no texto.

Os autores seguem no desenvolvimento dos assuntos, utilizando bastantes fontes pictóricas seguidas de legendas informativas que completam o texto escrito. O box História em Debate aparece mais uma vez, propondo uma pesquisa sobre o Império Bizantino. Mas não endereça a pesquisa, não oferece direção sobre onde conseguir dados sobre essa História. Um trecho de texto do bispo Eademer de Canterbury, que transmite os ensinamentos de Santo Augustinho, citado pelo historiador Le Goff, é posto em um box para exemplificar a organização social do período. É uma fonte histórica utilizada, também, como suporte para a fala dos autores.

A primeira atividade de interpretação do capítulo sugere, além da interpretação convencional do texto, uma leitura mais detalhada das imagens trabalhadas no capítulo. Uma questão propõe:

Ao longo deste capítulo existem várias imagens. Após observá-las, faça uma descrição da sociedade feudal. Procure perceber nas imagens, por exemplo, quais os temas abordados; quais personagens aparecem e quais estão ausentes (PILETTI; PILETTI, 2002, p. 15).

Como cada imagem possui uma legenda que completa o texto sobre aquele assunto, pouco sobra para o aluno ler apenas na imagem; as informações sobre a imagem são direcionadas. No entanto, percebe-se a intenção pedagógica de dar a resposta prevista, mas, para tanto, dever-se-ia desenvolver também a habilidade procedimental sugerida pelos PCNs. Outra vez a intenção de oferecer ao leitor o ato, ou a sensação do ato, de construir seu conhecimento parece óbvia. 
Nos dois boxes Oficina de História e Nosso Mundo Hoje ficam clara a intenção do fazer do aluno e, dessa vez, diferente das atividades mais direcionadas à interpretação, os leitores podem, além de interpretar a fonte, também organizar, relacionar, inferir, refletir. A Oficina de História traz um texto descritivo das tarefas rotineiras de um servo na região de Verson como fonte histórica para ser lido e interpretado. As orientações das tarefas localizam o leitor espacialmente ("na região de Verson, na atual França") e temporalmente ("escrito durante a Idade Média") e apresentam as atividades. Outra vez existe uma intenção muito clara de destaque nos conteúdos procedimentais. Ao organizarem uma linha do tempo, exploram conceitos, fatos, mas principalmente organizam os dados históricos, os tornam visíveis - procedimento que facilita a construção de reflexões. Essa última é mais explorada no próximo box Nosso Mundo Hoje. Após um texto adaptado da revista semanal IstoÉ n. 1681, de 20/12/2001, que denuncia trabalho escravo de garimpeiros brasileiros no Suriname, os autores apresentam um texto relacionando o trabalho escravo ao trabalho servil e propõem a atividade:

Releia o texto, anote as palavras que você desconhece e procure-as no dicionário ou em uma enciclopédia. Explique o que você entendeu do texto.

Compare a situação dessas pessoas submetidas ao trabalho escravo, de que trata o texto, com a situação dos servos na Idade Média. Faça um quadro comparando as diferenças e as semelhanças entre as duas formas de trabalho (PILETTT; PILET'TI, 2002, p. 17).

O texto não possui somente a função de comparar a servidão à escravidão, emite também um direcionamento das reflexões que propõe seguirem. "Releia o texto, anote as palavras que você desconhece e procure-as no dicionário, ou em uma enciclopédia. Explique o que você entendeu do texto.” Ler o texto novamente, após a leitura dos autores e a comparação dos conceitos, direciona um tipo de reflexão. Ao mesmo tempo em que a atividade se abre para uma polissemia, o direcionamento dos autores fecha a reflexão sem que o leitor note a prescrição. Em seguida, eles propõem: "Compare a situação dessas pessoas submetidas ao trabalho escravo, de que trata o texto com a situação dos servos da Idade Média. Faça um quadro comparando as diferenças e as semelhanças entre as duas formas de trabalho". 
Os textos abrem a atividade. Possui um atravessamento do discurso pedagógico, elabora e relaciona os conceitos e, principalmente, direciona as reflexões. Os referentes ausentes, servos e escravos, são significados a partir da fala do professor/autor. O leitor/aluno repete em forma de conceitos com a sensação de criação reflexiva. Mas esta sensação o aproxima do construtivismo. Trata-se de uma construção polissemicamente regulada. Esse é o funcionamento do discurso pedagógico. Nesse aspecto, os conteúdos atitudinais são provocados apenas na ordem do pensamento e da reflexão regulada.

O que esse discurso pedagógico, organizado dessa forma, diz? Existe um movimento do autor para dizer a sua versão sobre a História; porém existem possibilidades de ações do leitor, tanto na hora mesmo da leitura quanto nas atividades apresentadas. Com exceção daquelas atividades que apresentam objetivos claros de interpretação e síntese dos textos do capítulo, todas as outras podem ser desenvolvidas a qualquer momento da leitura do capítulo. O autor não impõe uma linearidade, ou seja, o capítulo pode ser estudado com um ritmo de idas e vindas, curvas, avanços e recuos. No entanto, os livros da coleção possuem uma organização de conteúdos convencionalmente linear. O traço do discurso pedagógico na tipologia educacional, nesse exemplo da coleção, é apuradíssimo, e, dessa feita, quase não precisa de que outras tipologias (histórica e imagética) tenham grande destaque para se apresentar prescritivo e sedutor ao mesmo tempo. Por pouco, ele seria autossuficiente.

O capítulo analisado neste artigo termina com um box chamado Textos e Contextos. Essa última situação do capítulo parece ser uma tentativa de apresentar uma História integrada. Os autores escrevem sob o título Um olhar sobre o Oriente:

Enquanto a sociedade feudal florescia na Europa Ocidental, o que acontecia no restante do mundo? Ali perto, na Europa Oriental, o Império Bizantino dominava, também com forte influência cristã. No Oriente Médio, o povo árabe unificava-se, graças à fé em Alá, e constituía um dos maiores impérios do período. $\mathrm{Na}$ América, isolada do restante do mundo, floresciam diversas sociedades, entre elas a dos maias. Entre todos esses lugares existia muito pouco intercâmbio. As distâncias, mais do que as diferenças culturais, faziam com que os povos de cada região se desenvolvessem isoladamente. Isso não afastava a curiosidade e o interesse por outras regiões. Na Europa Ocidental, por exemplo, existiam muitas lendas sobre povos distantes, donos de muitas riquezas e verdadeiros paraísos, como o reino de Prestes João e a Ilha Brazil [...] (PILETTTI; PILETTI, 2002, p. 18). 
A análise do texto permite perceber um funcionamento muito mais para confirmar uma desintegração do que a integração dessas Histórias. Durante todo o capítulo, a História da Europa Ocidental foi privilegiada. Somente na última atividade outros espaços fizeram parte do cenário do capítulo, com exceção da Europa Oriental, que apareceu como coadjuvante em outros trechos do discurso, foram citados o Oriente Médio e a América, com destaque para os maias, mas em seguida o texto volta para o centro - Europa Ocidental - e diz sobre a representação do centro em relação à "periferia" da História: "Na Europa Ocidental, por exemplo, existiam muitas lendas sobre povos distantes, donos de muitas riquezas e verdadeiros paraísos [...]". Assim termina o capítulo.

\section{REFLEXÕES FINAIS: AS LEITURAS QUE MARCARAM AS COLEC̣ÕES}

Como já é sabido, os PCNs orientam posturas pedagógicas que permitem ao aluno e ao professor se inscreverem no discurso politicamente correto, assim como o PNLD orienta os autores e as editoras. O que seria esse discurso? Aquele atravessado pelas diretrizes da tolerância? O discurso da tolerância nos documentos oficiais da educação possui uma intenção regulatória da produção social de uma identidade cidadã. O debate acerca da identidade e da diferença tornou-se central na oficialidade educacional, apesar de destacado às vezes como tema transversal. Focar o debate sobre construção, criação de identidades e diferenças na educação pressupõe, antes de tudo, um jogo de linguagem. Os livros didáticos de História são peças nesse jogo linguístico que diz o que é ser brasileiro, americano, europeu (identidade) e, ao mesmo tempo, não ser argentino, chileno, europeu (diferença). Essa produção simbólica e discursiva está sujeita a relações de poder, não é simplesmente definida, carrega, também, a arbitrariedade da língua, é imposta, é disputada. Segundo o educador Tomaz Tadeu da Silva,

[...] a identidade e a diferença estão, pois, em estreita conexão com relações de poder. $\mathrm{O}$ poder de definir a identidade e de marcar a diferença não pode ser separado das relações mais amplas de poder. A identidade e a diferença não são, nunca, inocentes (SILVA, 2000, p. 81). 
Como não são inocentes os jogos de sentidos produzidos nos materiais didáticos de História. O discurso da tolerância diante das diferenças produz na relação de poder uma neutralização de forças e um fortalecimento da identidade. Por exemplo, na coleção História \& Vida Integrada, ao não utilizar a palavra bárbaros e privilegiar termos politicamente corretos, como povos de origem germânica, retira-se o sentido pejorativo do outro. Um tratamento positivado ao eles neutraliza qualquer sentimento de revanche e faz com que não se precipitem sobre qualquer que sejamos nós. Isso não significa efetivamente que não se entenda aquela invasão como bárbara.

O mesmo acontece, em outro exemplo, na mesma coleção, quando os autores, ao referirem a chegada dos europeus na América, escolhem as palavras Europa e América: um duplo descobrimento, ou, ainda (Des) encontro de culturas. O que existe nesse jogo de sentidos? Não somente um eles que descobriram a nós (eles, ativos, e nós, passivos), mas um nós também ativo: duplo descobrimento. $\mathrm{O}$ segundo título revela a tensão entre essas diferenças culturais, a negação no prefixo "des".

É possível observar as intenções de positivar o nósno discurso dos autores. E de tratar o eles sem desclassificação. A marca da tolerância anunciada tanto nos PCNs quanto no PNLD. Ao escrever sobre a independência do Brasil, os autores usam a palavra soberania (PILETTI; PILETTI, 2002, p. 126), por exemplo. Não se trata aqui de discutir o conteúdo factual da História, mas a forma como se apresenta esse conteúdo. E o jogo do nós e eles. "As elites brasileiras passaram então a organizarem-se para separar o Brasil de Portugal, o que aconteceria em 1822, com a Proclamação da Independência.’(PILETTI; PILETTI, 2002, p. 126). Pouco importa a verdade dos fatos, mas a narrativa que funda o acontecimento funciona para dar uma identidade fundada em uma estratégia sentimental e afetiva e, nesse caso, positivada, no que tange à relação do nós, brasileiros, com os outros, eles, os portugueses. O local politicamente correto, incentivado muitas vezes pela tolerância, talvez seja um grande traço dessa coleção. Porém, ele possui um limite quando escolhe falar sobre as desigualdades sociais. Sobre esse assunto, o texto expõe de forma mais clara um local de fala que permite agenciamentos coletivos em consonância com as causas dos menos favorecidos. Isso pode ser um lado do politicamente correto, todavia o funcionamento desse discurso pode provocar também revoltas e transgressões não tão esperadas e não desejadas pelo Estado. 
Por outro lado, a coleção Nova História Crítica possui outra marca. Seu destaque está nos embates das relações entre classes sociais distintas. Isso aparece de forma mais evidente e caricaturizada quando se utiliza de frases como "Servos contra senhores" (SCHIMIDT, 2002, p. 32), "Os servos se rebelam" (SCHIMIDT, 2002, p. 34), por exemplo, expondo marcas, no texto, de um entendimento sobre o mundo a partir de uma divisão social em dois polos opostos, e isso acaba direcionando todo o texto.

Além disso, o grau de polissemia que o texto oferece, pautado na tipologia do discurso pedagógico, o coloca em uma posição muito autoritária e dona de uma verdade única. O referente apresentado nos textos de História, os fatos históricos, as narrativas históricas estão ausentes, já são passado. E a posição do sujeito autor é muito forte, ele ocupa um papel de professor em uma aula expositiva. $\mathrm{O}$ texto fala sobre um referente ausente, a partir de leituras do autor sobre esse referente. Ao leitor fica apenas a leitura do autor sobre outras pesquisas, uma visão sobre o referente. Dessa forma, o sentido que fica no texto é o da luta de classes. Uma luta raivosa, uma visão enfurecida das relações de classe e do liberalismo.

Todos esses esforços do discurso dos livros didáticos são para fazer funcionarem sentidos de democracia, de cidadania e, principalmente, para oferecer subsídios aos jovens que lhes possibilitem construir narrativas históricas. E, para que, no ato dessas construções, a materialização de subjetividades cidadãs tome seu curso, num momento tanto de leitura do livro quanto de produção de narrativas, de regular os sentidos nessas subjetividades em processo. 


\section{REFERÊNCIAS}

BITTENCOURT, C. M. F. Em foco: História, produção e memória do livro didático. Educação e Pesquisa, São Paulo, v. 30, n. 3, p. 471-473, set./dez. 2004. http://dx.doi. org/10.1590/S1517-97022004000300007

BITTENCOURT, C. M. F. Ensino de História: fundamentos e métodos. 2. ed. São Paulo: Cortez, 2008.

BRASIL. Secretaria de Educação Fundamental. Parâmetros Curriculares Nacionais: Introdução. Brasília: MEC, 1998.

BRASIL. Ministério da Educação. Guia do PNLD 2005 - $5^{a}$ a $8^{a}$ Série do Ensino Fundamental. Brasília: Secretaria de Educação Básica, 2005.

CHARAUDEAU, P.; MAINGUENEAU, D. Dicionário de análise do discurso. São Paulo: Contexto, 2004.

MALDIDIER, D. A inquietação do discurso: (re)ler Michel Pêcheux hoje. Tradução de Eni Orlandi. Campinas: Pontes, 2003.

MIRANDA, S. R.; LUCA, T. R. O livro didático de História hoje: um panorama a partir do PNLD. Revista Brasileira de História, São Paulo, v. 24, n. 48, p. 123-144, 2004. http:// dx.doi.org/10.1590/S0102-01882004000200006

MUNAKATA, K. Grupo de Trabalho 7. Livro Didático: Produção e uso dos saberes escolares. In: ENCONTRO NACIONAL DOS PESQUISADORES DO ENSINO DE HISTÓRIA, 7., 2006, Belo Horizonte. Anais... Belo Horizonte: UFMG, 2006.

ORLANDI, E. A Linguagem e seu Funcionamento: as formas do discurso. 4. ed. Campinas: Pontes, 2003.

ORLANDI, E. Interpretação: autoria, leitura e efeitos do trabalho simbólico. Campinas: Pontes, 2002.

PILETTI, N.; PILETTI, C. História \& Vida Integrada. São Paulo: Ática, 2002. FONTES

SCHIMIDT, M. F. Nova História Crítica. São Paulo: Nova Geração, 2002.

SILVA, T. T. A produção social da identidade e da diferença. In: SILVA, T. T. (Org.). Identidade e Diferença: A perspectiva dos Estudos Culturais. Petrópolis: Vozes, 2000. 


\section{NOTAS}

${ }^{1}$ São de inteira responsabilidade da autora os conteúdos e ideias expressos nesta pesquisa. ${ }^{2}$ Em especial a Coleção Nova História Crítica projetou-se como a mais escolhida no país, entre todas as coleções apresentadas aos professores no Guia do Livro Didático de 2005. O jornal O Estado de S. Paulo chegou a anunciar posteriormente que o Ministério da Educação dava conta de que 30\% da compra de livros didáticos de História feita pelo MEC em 2005 foi especificamente dessa coleção. Disponível em <http:/ /www.estadao. com.br/noticias/impresso,20-milhoes-utilizaram-livro-polemico,54753,0.htm > . Acesso em: 12 dez. 2012.

Recebido: 26/10/2011

Aprovado: 25/02/2013

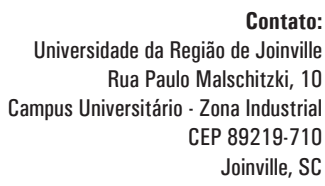

Joinville, SC

Brasil 